\title{
Três consideraçóes sobre a "má medicina"
}

\section{Charles Dalcanale Tesser ${ }^{1}$}

TESSER, C.D. Three considerations about "bad medicine". Interface - Comunic., Saude, Educ., v.13, n.31, p.273-86, out./dez. 2009.

\begin{abstract}
Some considerations are made about "bad medicine": a set of individual and collective phenomena regarding the usual disharmony, dissatisfaction and disappointment experienced by sick people in the doctorpatient relationship. The purpose is to contribute to a better understanding of such "bad medicine", taking its complexity into account, and also to collaborate with its improvement. We disagree with the common sense that summarizes such failed encounters as "bad medical practice". We argue that some of its typical aspects, such as authoritarianism, arrogance, coldness, excessive control, belligerency, and the feelings of omnipotence and omniscience of so many physicians are intertwined with historical-epistemological, social-political and sub-cultural factors of these professionals; for instance, the political victory of Science and its ethnocentrism, biomedicine's official monopoly of cure, the current expansion of the biomechanical paradigm, the authoritarian culture in the hospital setting, the unquestioned adoption of a scientific prejudice against non-science, among others, besides wider and more complex processes like social medicalization.
\end{abstract}

Keywords: Medicine. Physician-patient relations. Professional misconduct. Sociology. Anthropology.
Realizamos algumas considerações sobre a "má medicina": um grupo de fenômenos individuais e coletivos referentes à comum desarmonia, insatisfação e frustração no encontro médico-paciente vividos pelos doentes. Visamos contribuir para uma melhor compreensão dessa "má medicina", considerando sua complexidade, e para a sua melhoria. Divergimos do senso comum e douto que resume tais desencontros como "má prática" médica. Argumentamos que alguns de seus aspectos típicos, como autoritarismo, arrogância, frieza, controlismo, beligerância, sensação de onipotência e onisciência de muitos médicos estão entrelaçados com forças ou fatores histórico-epistemológicos, sóciopolíticos e subculturais desses profissionais, como a vitória política da Ciência e seu etnocentrismo, o monopólio oficial da cura pela biomedicina, a vigência e expansão nela de um paradigma biomecânico, a cultura autoritária hospitalar, a adoção cega do preconceito científico com a não-ciência, dentre outros fatores, além de processos mais amplos e complexos como a medicalização social.

Palavras-chave: Medicina. Relações médico-paciente. Má conduta profissional. Sociologia. Antropologia.
${ }^{1}$ Departamento de Saúde Pública, Centro de Ciências da Saúde, Universidade Federal de Santa Catarina. Rua Laureano, 970,

Campeche, Florianópolis, SC, Brasil. 88065-040 charlestesser@ccs.ufsc.br 


\section{Introdução}

Não é raro acontecer de pessoas procurarem ajuda médica e encontrarem profissionais pouco acolhedores, mais ou menos arrogantes, ríspidos, pouco amigáveis, indelicados, alguns até grosseiros em certa medida, que não "olham na cara". Em tais encontros, frequentemente há aumento da insegurança, insatisfação e frustração nos doentes, denotando uma desarmonia relativamente comum nessa relação.

Tomamos, como objeto de reflexão, esse fenômeno designado no título como "má medicina", plagiando o jargão profissional que fala em "má prática". Nossa hipótese é que a má medicina não pode ser resumida à chamada má prática. Sendo mais do que a corrupção de uma suposta boa prática, ela é fomentada por um conjunto de aspectos constitutivos da biomedicina. Não se trata de contrapor uma boa a uma má prática médica, mas sim de explorar a complexidade de aspectos histórico-epistemológicos, culturais, pedagógicos e sociopolíticos envolvidos na biomedicina, que alimentam a má medicina.

Esse fenômeno é facilmente reconhecível a partir da vivência dos doentes e, também, a partir do ponto de vista de certo saber/fazer acadêmico/artístico especializado, que contribui para sua compreensão - como em Kloetzel (1999) e Stewart et al. (1995) - e que permite reconhecer uma "boa medicina", a qual, entretanto, não será objeto de nossa atenção. De fato, a literatura médica e da Saúde Pública, há muito tempo e persistentemente, debruça-se sobre os problemas da relação médico-paciente e da atividade médica - Balint (1988), Illich (1981), Clavreul (1983), e, no Brasil, mais recentemente, por exemplo: Caprara e Franco (1999), Camargo Jr. (2003), Caprara e Rodrigues (2004), Guedes, Nogueira e Camargo Jr. (2006), Camargo Jr. (2008).

Não é necessário definir ou precisar a má medicina, dado que não se trata de um novo objeto ou categoria a ser bem delineada. Poder-se-ia, talvez, dizer que se trata do problema da "relação ruim médico-paciente", apenas por conveniência chamado de má medicina, à falta de um termo melhor e sintético. Mas esta expressão, relação médico-paciente, embora consagrada, pode remeter a dicotomias que nos esforçamos por evitar (por exemplo, saber versus prática), e tende a reduzir, de certo modo, o problema, induzindo a desvinculá-lo de outras dimensões que justamente pretendemos explorar.

Há um senso comum e certo senso douto que atribuem essas experiências, desarmonias e frustrações, no encontro clínico, à má prática médica. Essa visão preza a separação entre os "aspectos contextuais", muito influentes sobre a prática da biomedicina ${ }^{2}$, e um núcleo conceitual da mesma, que teria seus "fundamentos teóricos" alhures, na Ciência, aos quais não caberia crítica (Pires, 1998), pois pouco envolvimento teriam com a má prática. Neste ensaio partimos de uma perspectiva diversa, baseada em Latour (2001, 2000a, 2000b), na qual essa separação entre núcleo conceitual e contexto sócio-histórico é indesejável porque dificulta a compreensão da complexidade do fenômeno, que é intrinsecamente híbrido (envolvendo saberes, poderes, histórias, culturas, afetos, técnicas, tecnologias etc). Nossa abordagem trata conjuntamente alguns destes aspectos da rede sociotécnica (Latour, 2000b) constitutiva da medicina moderna, e considera esta inseparabilidade como necessária e estratégica para uma compreensão, sempre parcial, das complexidades envolvidas, com vistas à melhoria de sua prática cuidadora.

A proposta é uma reflexão de inspiração genealógica e sócio-histórica sobre alguns aspectos e forças envolvidos na atividade médica e seu saber fomentadores da má medicina, que atravessam tanto dimensões individuais e práticas como sociais, corporativas e epistemológicas. O método genealógico busca explorar

\author{
${ }^{2}$ Usamos o termo \\ biomedicina para \\ designar a medicina \\ ocidental \\ contemporânea, que \\ abarca dois conjuntos \\ que, para nossos \\ objetivos de \\ compreensão da má \\ medicina, devem ser \\ considerados \\ integradamente: 0 \\ primeiro é o grosso da \\ prática profissional dos \\ médicos do ocidente, \\ que apresenta \\ impressionante \\ homogeneidade frente a \\ tradições e práticas \\ curadoras de origem não \\ científica ou não \\ acadêmica. Portanto, \\ esse primeiro significado \\ do termo pode ser \\ resumido como "a \\ biomedicina é o que os \\ médicos fazem". O \\ segundo significado do \\ termo refere-se ao \\ conjunto de saberes, \\ valores e técnicas que \\ informam a prática social \\ designada pelo primeiro \\ significado, de cunho \\ cada vez mais científico \\ e especializado, em \\ mudança permanente \\ (mas também com \\ relativa homogeneidade \\ e continuidade ao longo \\ das últimas décadas, \\ sobretudo nos seus \\ aspectos aplicáveis e \\ aplicados ao cuidado, à \\ prática clínica).
}


redes e origens (valores, emoções, forças, desejos, interesses, poderes) que orientam, influenciam e constrangem culturas, práticas sociais e saberes (Martins, 2004). A reflexão não se propõe a realizar uma genealogia propriamente dita, mas refletir sobre elementos genealógicos associados a outros fatores envolvidos com a má medicina, ensaiando algumas hipóteses interpretativas a respeito.

Abordaremos a má medicina sob alguns poucos ângulos, como aspectos da iniciação dos profissionais, do saber e da ação médica, com ênfase condutual e emocional: a arrogância e o autoritarismo, a beligerância e o controlismo, a missão imaginária do herói solitário e o peso dessa missão impossível. Esse três pares de "características", comumente criticadas e presentes na má medicina, são interligadas entre si e vinculadas com forças das mais diversas naturezas. Neste ensaio propomos reflexões e especulações que se destinam a contribuir para o incremento da compreensão da complexidade nelas embutida, bem como de sua persistência na prática e no ensino médicos.

Embora muito denunciada e, por vezes, considerado esgotado o seu debate, a consideração e análise da má medicina são relativamente dispersas e pouco sistematizadas na literatura. Parece-nos relevante sua abordagem para uma melhor avaliação das dificuldades de formação dos médicos e dos desafios da reforma dessa prática profissional. Isso é ainda mais importante para gestores do Sistema Único de Saúde (SUS) e para profissionais da atenção primária à saúde, em época de expansão dessa última, via Estratégia Saúde da Família e de intensa medicalização social da vida e dos riscos individuais e coletivos. Nesse ambiente que clama por uma "clínica ampliada", uma educação em saúde "empoderadora" e mais integralidade nos serviços e nos profissionais, é relevante relembrar a grande dimensão do problema (Caprara, Rodrigues, 2004) e investigar origens e complexidades do mesmo.

\section{Arrogância e autoritarismo}

O senso comum e a ciência nasceram juntos. Segundo Santos (2000), o senso comum foi o nome dado às formas de conhecimento que não correspondessem aos critérios epistemológicos estabelecidos pela ciência para si própria. A diferenciação epistemológica pretendida pela Ciência em relação ao senso comum foi precisa: tratou-se de erigir uma instância acima e supostamente desvinculada das tradições e religiões, que seria o critério supremo de avaliação do que é e do que não é verdadeiro, a Ciência.

A construção do senso comum igualou tudo aquilo que ficou fora da Ciência: um conjunto heterogêneo de práticas e saberes (populares e especializados) que ficou sendo considerado homogêneo e pobre do ponto de vista epistemológico ${ }^{3}$ e, também, agregado num conluio político-cultural que mantinha os homens presos na obscuridade, de caráter conservador e indesejável. Assim, a ciência moderna considera o senso comum superficial, ilusório e falso (Santos, 2006).

Essa desconfiança básica, se é um dos motores da ciência para a mesma fazer sua primeira ruptura epistemológica (Santos, 1982) na construção do conhecimento científico, hoje se revela problemática pelo seu lado destrutivo e dominador de outros saberes, assim como pela sua arrogância e preconceito, que, todavia, não são exclusividade da ciência e nem foram inaugurados por esta. Nossa hipótese é que certa arrogância preconceituosa e etnocêntrica da ciência encontra afinidades eletivas ou mesmo antecedentes histórico-culturais anteriores à modernidade.

Numa perspectiva macrocultural e histórica, encontramos traços de uma arrogância etnocêntrica na antiga cultura religiosa judaico-cristã, desenvolvida na 
Europa com o cristianismo e exportada para o planeta a partir da expansão européia após o século XV. Joseph Campbell (1993) ilustra esse etnocentrismo comentando a peculiaridade da religião judaica perante o grosso das religiões do mundo, politeístas. Segundo o autor, na maior parte destas últimas, os deuses principais eram universalistas e os deuses bairristas ou tribalistas eram secundários, invocados para proteção do povo em períodos de guerra. Ao fim das batalhas, era possível a construção de sincretismos e era comum um relativo respeito pela cultura dos perdedores, devido às equivalências que se podiam fazer entre as divindades dos diferentes povos. Com isso, os diferentes mitos, deuses, verdades, ciências e sabedorias podiam ser reconhecidas e se entrecruzar, se transformavam ao mesmo tempo em que se preservavam. Porém, essa possibilidade ficou dificultada quando a cultura e a religião dos vencedores eram tribalistas e monoteístas, seu Deus era único: o que foi o caso da religião judaico-cristã. lavé é o Deus único, os demais são demônios, e os mitos, saberes e culturas dos povos "pagãos" perdem respeito e sabedoria, ficam dignos apenas de combate e desqualificação.

Resumindo a história, poderíamos dizer que uma religião tribalista e monoteísta misturou-se com a cultura beligerante e dominadora européia que se expandiu pelo mundo. Quando essa cultura derruba seu próprio deus e o substitui pela Ciência, como única instituição social produtora de verdades, em posição mitológica (Feyerabend, 1991), esta, que já nascia com uma proposta nada modesta - revelar as verdades - ficou embebida e reconstruiu essa arrogância etnocêntrica que desqualifica tudo o que não é ela mesma.

A digressão acima prepara o terreno para chegarmos à área da saúde-doença e à profissão médica, em que desdobramentos subculturais, emocionais e políticos da vitória da guerra da ciência foram provavelmente relevantes, e a hipótese aqui trabalhada é de que sejam mais importantes do que se imagina, atingindo os interstícios atuais da técnica, da clínica e do relacionamento com os doentes. Não é necessário traçar detalhes e complexidades desses desdobramentos no Ocidente, basta marcar o que é mais relevante para nossa reflexão: a oficialização dos médicos nos séculos recentes, como únicos curadores legítimos, representantes da Ciência, portadores da verdade, legitimados pelos Estados ${ }^{4}$ (Adam, Herzlich, 2001). A autonomização da profissão perante a sociedade foi a pedra de toque culminante da trajetória política da medicina. Tal trajetória possivelmente ajudou a veicular uma tradição de arrogância e etnocentrismo científicos para o interior desses especialistas oficiais em saúde-doença. De modo que a arrogância em sentido geral pode não ser fruto de característica pessoal ou circunstancial da má prática médica. Uma parte relevante dela poderia ser remetida à herança cultural científica. Herdeira dessa luta e dessa conquista política, a biomedicina está, por um lado, impune e assegurada na posição de poder, o que facilita a arrogância; e, por outro lado, "sente-se" permanentemente ameaçada pela miríade de tradições, técnicas, saberes, práticas e curadores que sobrevivem socialmente, diferentes dela mesma e, paradoxalmente, cada vez mais procurados (Le Fanu, 2000).

Mas como se infiltraram, na mentalidade, na cultura clínica e no cotidiano de razoável número de médicos, essa arrogância e esse autoritarismo? O nascimento da clínica e seu aprendizado no hospital, bem como seu desenvolvimento históricoepistemológico apoiado no "paradigma biomecânico" 5 (estabilizado e detalhado no século XX, em pleno vigor no século XXI com a biologia molecular e a genética), facilitam uma compreensão parcial desse processo, associados à arrogância proveniente da Ciência e à agressividade política das suas lutas iniciais contra a Igreja, dentre outras forças importantes (inclusive de ordem político-econômica).

Os médicos aprendem biomedicina eminentemente no hospital. O comum autoritarismo médico pode ser interpretado como uma herança cultural e
${ }^{4}$ Posteriormente acompanhados por outras profissões da saúde que foram se regulamentando oficialmente.

${ }^{5}$ Pode-se dizer que o paradigma biomecânico envolve um concepção ontológico-localista e mecânico-causal das doenças, em que estas são vistas como coisas concretas, defeitos ou disfunções do organismo físico, relacionadas a lesões materiais, a serem investigadas no interior do corpo físico e corrigidas com alguma intervenção concreta (medicamentos e cirurgias) (Camargo Jr., 2003). O uso do termo kuhniano "paradigma" aqui é em sentido estendido ao saber e à atividade médica baseado na sua semelhança com o conceito de estilo de pensamento, de Ludwik Fleck (1986), conceituado de forma mais genérica e aplicável a um coletivo de pensamento portador de uma formação especializada com interesses e atividades específicos (Tesser, 2008). 
psicossocial enraizada no proceder médico, talvez amplificada pela subcultura médica do hospital, o qual é, nitidamente, autoritário desde seu nascimento enquanto instituição médica. Para Foucault (1980), essa característica é historicamente herdada da instituição militar, e fez o hospital ser considerado como uma instituição quase-total, a exemplo dos manicômios, conventos e prisões (Goffmann, 1974). O autoritarismo no hospital é aceito e, relativamente, não causa muitos problemas. Ali, o paciente delega o poder para os profissionais. Discussão ou recusa de uma conduta médica, num hospital, é coisa rara, estranha, e, muitas vezes, significa alta a pedido. Desnecessário enfatizar que o autoritarismo não é tema de discussão no hospital. É vivido e praticado no ambiente, nas regras, nas relações e está embutido no imaginário social hospitalar, cristalizado em regras e normas inflexíveis. O médico, ao prescrever num hospital, não tem o paciente à sua frente, não fala com ele, não precisa explicar os diagnósticos e as condutas. Estas explicações, quando ocorrem, são rápidas e realizadas em momento à parte, muitas vezes apenas com um familiar, geralmente separadas da decisão e prescrição terapêutica. Feita a prescrição, ela será automaticamente executada sobre um doente paciente e submisso, que receberá, da enfermagem, uma curta resposta às suas perguntas sobre o tratamento: é para a dor, é contra a infecção. O tempo do contato terapêutico no hospital é pequeno e os critérios de internação e alta definem os objetivos dos profissionais e o tempo de contato com o doente, além de constrangimentos outros institucionais e sociais - filas para internação etc. Estes critérios e estes tempos produzem expectativas, prioridades e certa sensação de eficácia, os quais estão pautados pelo diagnóstico e intervenção na doença, sendo referidos à sua cura ou controle, com a saída do doente da situação de gravidade geradora da internação. Por isso mesmo, a intervenção é e deve ser sempre rápida, seu efeito e sua eficácia devem ser sentidos rapidamente, para o que não se poupa tecnologia investigativa e terapêutica "duras".

Dentro do hospital a percepção dos danos (iatrogenias) é muito menor, não só pelo pouco tempo de contato, como pela naturalização de alguns deles. Além disso, dada a situação clínica de alta gravidade e de extrema assimetria de poder, a tolerância dos pacientes internados aos danos é muito grande. A atenção hospitalar é voltada para o risco biológico, e pouco tem a ver com a vida do doente préinternação ou pós-alta. A gravidade da situação orgânica no hospital permite que o aspecto biológico se destaque, fornecendo uma sensação de suficiência do saber biomédico (Cunha, 2005). Nos hospitais, bem como na biomedicina em geral, há a tendência para a fragmentação do cuidado por especialidades, de forma que, na medida em que aparecem outras doenças, estas vão sendo distribuídas pelas especialidades que se responsabilizam por patologias específicas, submetendo o doente a um esquartejamento epistemológico irreversível (Tesser, 2004).

Esse mergulho no hospital permite compreender quão comuns são os problemas quando muitos médicos se defrontam com a imensa maioria de pacientes independentes, que esperam acolhimento emocional, explicações que Ihes façam sentido, acalmem e preparem para a terapêutica, e terapêuticas compreensíveis e factíveis. Ou seja, a maior parte da vida profissional do médico é ambulatorial (exceção feita a algumas especialidades), em que quase nenhuma daquelas condições especiais de autoridade, controle, rapidez, eficácia, objetividade e necessidade de intervenção imediata controlada aparecem. E, obviamente, muitos não foram preparados adequadamente para lidar com os doentes independentes em suas condições reais de existência, mesmo supondo "ótimas" ou "ideais" condições socioinstitucionais para a prática médica.

O aprendizado da clínica, no hospital, pelos profissionais foi e continua sendo provavelmente uma força importante no processo pedagógico-iniciático: vários anos de formação (pelo menos seis; oito ou mais anos considerando as residências médicas) numa instituição autoritária são essenciais para a introjeção da arrogância e do autoritarismo em muitos médicos. Adicionalmente, o desvio da atenção para o "olhar as lesões" (em detrimento do escutar o doente), marcador do nascimento da clínica (Foucault, 1980), fantasticamente hipertrofiado com o desenvolvimento tecnológico diagnóstico recente, certamente ajudou e fortaleceu esse processo. Esse desvio do olhar, que vê tendencialmente as pessoas doentes como portadores de "doenças" e, recentemente, riscos, que passam a ser os objetos principais da atenção do médico (Camargo Jr, 2003; Mendes Gonçalves, 1994), foi desenvolvido a tal ponto que talvez seja por si mesmo outro dos fatores importantes para a compreensão de tantos desencontros entre médicos e doentes.

Assim, a arrogância e o autoritarismo biomédicos podem ser relacionados a uma característica cultural e histórica geral do ocidente europeu, possivelmente reforçada na subcultura da corporação 
médica, aprendidos na prática e pelo seu lado "interno" no locus formador - o hospital -, e pela sua relação "externa" com a sociedade, como fruto de sua vitória política associada à Ciência, que colocou esta em um lugar seguro, garantido e com o poder de dizer a "verdade". Tal trajetória de relacionamento da biomedicina com a sociedade torna plausível a hipótese de que haja uma forte influência do ambiente macropolítico para o ambiente microssocial da clínica, por meio do processo que permite a manutenção permanente e renovada da arrogância-autoritarismo, atualizando essa característica e sustentando um habitus profissional em parte da corporação, no sentido de Bourdieu (1994). Tal processo pode ser resumido em poucas palavras: a impunidade gerada pelo monopólio oficial do exercício da atividade curadora na sociedade e a legitimidade daí decorrente, garantidas no "atacado", foram afastando as técnicas relacionais e a percepção ética, emocional e cotidiana da necessidade da legitimação dos profissionais e da relação de cura no "varejo", no cotidiano do contato com os doentes. Ou seja, a posição social do médico enquanto curador é estável e está garantida: ele pode, e essa possibilidade é coerente com o que vem acontecendo com parte dos profissionais, "descuidar-se" de se legitimar como curador no dia-a-dia (Tesser, Luz, 2008).

Adicionalmente, tal processo é facilitado pelas características do saber médico que permitem e alimentam o ideário de que uma eficácia e uma correção técnicas podem se dar à revelia da ancestral relação curador-doente, ideário de origem eminentemente científica. A promessa iluminista e positivista científica de eficácia dada pela elucidação dos mecanismos da doença e pela intervenção material específica sobre eles certamente alimentou e alimenta a crença (dificilmente assumida) de que se poderia prescindir do nebuloso emaranhado psicossocial da relação curador-doente. Porque os médicos seriam honestos, científicos e eficazes, poderiam dispensar esses meandros subjetivos e sacerdotais da relação de cura, cuja "eficácia simbólica" (ou efeito placebo) foi atribuída aos curadores pré-científicos, não sem projetar neles uma dose de charlatanismo, como ilustrado por Lévi-Strauss (1976) na história famosa de Quesalid.

A associação entre herança político-cultural, hospitalar e epistemológica talvez seja forte o suficiente para que, mesmo em locais de trabalho onde supostamente a reconstrução dessa relação ancestral de cura interessa direta e economicamente ao médico, como na medicina privada, não é raro que vários profissionais tenham se mantido muitas vezes arrogantes, pouco comunicativos e frustrantes para seus pacientes. Tais heranças se fundem e cristalizam, levando à perda da legitimidade no varejo e à indiferença frente a essa perda, ao não-aprendizado prático da necessidade da continuada reconstrução da legitimidade, com a consequente fragilização da harmonia emocional e relacional entre curadordoente, abalando de forma profunda "a relação de cura", na prática, de parcela dos profissionais em muitas situações.

\section{Beligerância e obsessão pelo controle}

Outra característica da má medicina é a beligerância e a obsessão por controle. Sintetizamos, nessas palavras, várias características, valores e posturas da prática biomédica: intervencionismo, agressividade, pressa, controlismo, desconfiança, tensão emocional etc.

Já antecipada acima indiretamente, a beligerância biomédica também pode ser perscrutada na histórica luta da Ciência com a natureza em geral, como explicitada por Francis Bacon nos seus primórdios, e mesmo antes do nascimento da ciência, na cultura geral da Europa. Para Turner (1990), o ocidente europeu vive, há muito tempo, uma tensa e belicosa relação com a natureza, particularmente acirrada após o rompimento com a cosmovisão mítica e o nascimento de uma perspectiva religiosa histórica: a religião cristã que se espalhou na Europa. $O$ autor descreve, em detalhes cruentos, essa relação, quando dos primeiros anos da expansão Européia, no século $X V$, na colonização do novo mundo americano. Analisa a transformação dos nativos em seres da natureza (quase por oposição a seres humanos) e a incapacidade dos Europeus de perceberem, relacionarem-se de forma não agressiva e respeitarem as riquezas culturais e naturais que transbordavam neste então lugar continental paradisíaco, porém totalmente diferente e "selvagem" em relação à Europa "civilizada".

Adicionalmente, na história européia e da medicina ali, durante a Idade Média e o nascimento da modernidade, as repetidas guerras e grandes epidemias que assolaram o continente contribuíram 
também, de certa forma, para a construção de um "estado de espírito" cultural tenso e beligerante quanto à saúde-doença. Particularmente com relação ao saber científico biomédico nascente dos séculos $\mathrm{XVI}$ a XX, o medo e a agressividade referentes às doenças e à própria natureza, a ser dominada pela Ciência em formação e, depois, consolidação, promoveram uma mentalidade beligerante perfeitamente em consonância com a arrogância e o autoritarismo.

Como resultado dessa história, podemos sintetizar que, em geral, a relação do homem moderno e, em especial, a do médico para com a natureza, por um lado, é de desconfiança hostil e medo e, por outro lado, é de otimismo intervencionista quanto ao poder da tecnologia científica. A outra face desse otimismo intervencionista é um claro pessimismo quanto às potencialidades curadoras autóctones dos doentes e as possibilidades de estímulo a elas, geralmente pouco exploradas pela pesquisa, pelo saber e pela prática médica (exceção feita, sobretudo, às tecnologias preventivas de imunização).

A subjetividade, o "estado de espírito" ensinado aos praticantes da tradição biomédica, é um misto de alerta, agressividade defensiva, atenção para os mínimos indícios dos inimigos mortais (as doenças graves), frieza, tendência interventora e vigilância controladora. Grosso modo, é como uma inimiga que a ciência biomédica vê a natureza. Após analisá-la, a reconstrói como modelo ideal, reduzida às partes materiais passíveis de manuseio, senão agora, no futuro. Assim, a Ciência conhece, a seu modo, parte da natureza, aquela parte que ela concebe e reconstrói em seus modelos, mas essa é uma natureza reconstruída e dominada, tecnicamente feita, desprovida de qualquer interioridade e vida, reduzida a um mecanismo complicado (Müller, 1996).

Muitas culturas consideraram a natureza como uma aconchegante e dadivosa mãe, ainda que tivesse seus momentos de fúria e desequilíbrio (intempéries, doenças etc). Viram-na com caráter predominante de doação e nutrição generosa, sábia, maternal, amistosa e poderosa. Todavia, para a modernidade e muitos de seus médicos, ela é uma permanente ameaça que deve ser controlada, monitorizada e vigiada. As doenças, legitimadas e objetivadas pela construção científica das entidades nosológicas (e dos riscos), converteram-se em inimigos naturais e, como se tivessem vida própria, parecem estar, a cada paciente, sintoma e/ou exame, prestes a atacar. Assim, a saúde humana parece frágil e carece de vigilância profissional, tecnológica, contínua, intensiva ou periódica. Algo similar a uma "paranóia" está em vigor alertando muitos médicos sobre o perigo da imensa lista de doenças graves que estão sempre por perto e que podem se travestir de sintomas aparentemente banais ou comuns.

No hospital, local de doentes graves, onde essas patologias se fazem presentes de forma acentuada, o perigo de vida e o medo da morte estão na sua expressão e intensidade máximas. A guerra no hospital é declarada e, muitas vezes, real. As capacidades próprias dos doentes estão quase sempre insuficientes e fracassadas, a gravidade é grande, o belicismo é aceito, a intervenção agressiva, precoce e controladora é, muitas vezes, necessária e salvadora. O fato de, no mundo extra-hospitalar, os adoecimentos serem muito diferentes, na sua maioria benignos (outros tantos se instalam e evoluem lentamente, com idas e vindas), e as curas e convalescenças se darem por múltiplos e complexos, inclusive autóctones, poderes, não altera a mentalidade, os automatismos emocionais, os medos e as posturas que muitos médicos aprenderam no hospital: o "filme de terror" aprendido nas aulas, as doenças graves e, mesmo, as trágicas histórias reais de pacientes, acompanhados nos anos de formação nos hospitais, marcarão por muito tempo as mentes e os corações de boa parte desses curadores.

A beligerância e o controle para com a natureza e, na saúde, em relação às doenças e, mesmo, aos doentes, são quase que indissociáveis. O controle pode ser considerado uma parte da beligerância, mas desdobrou-se de tal forma nos procedimentos científicos e biomédicos, bem como na sua subcultura profissional, que merece tratamento mais detido. Ele é a forma operacional pela qual a beligerância se expressa e se concretiza nas práticas e nos saberes científicos e biomédicos. Além disso, o controle configurou-se como um dos pontos centrais da racionalidade científica moderna, ocupando lugar central em disputas envolvidas nas discussões epistemológicas e metodológicas da biociência sobre os saberes e intervenções terapêuticas (Tesser, 2007).

A ciência é permeada por outros valores além dos chamados cognitivos - como adequação empírica, consistência, simplicidade, fecundidade, poder explicativo e verdade. Os valores cognitivos são defendidos, em geral, como os únicos e essenciais, tanto descritivamente como prescritivamente, para caracterizar e orientar a Ciência. Lacey (1998) aceita que os valores cognitivos prestigiados pela ciência 
moderna possam ser separados relativamente dos demais valores sociais e que sejam cruciais na pesquisa científica, mas ressalta que "sua interpretação é sempre estruturada por alguns valores sociais, e o apoio à sua expressão é ligado à expressão de certos valores sociais" (Lacey, 1998, p.177).

O controle está visivelmente associado a valores cognitivos como preditibilidade e reprodutibilidade, e pode ser considerado o valor central na empreitada científica (Lacey, 1998), de fundo simultaneamente político, social e psicológico. Ele dirige-se inicialmente à natureza e, mais especificamente, ao controle dos objetos materiais. Esse enfoque constitui-se na maior e mais bem-sucedida (em termos de hegemonia social na comunidade científica) estratégia de restrição e seleção de dados e fenômenos como base empírica para teorias e, posteriormente, como mundo a ser controlado. Tal estratégia de seleção e restrição de dados é chamada, por Lacey (1998), de "estratégia materialista". Para esse autor, a maior vantagem da estratégia materialista é justamente o fato de ela ser possivelmente a melhor para propiciar o controle. Seria disso que decorre o sucesso da ciência, e não da proeminência dos valores cognitivos nela.

Na saúde, a razão biomédica é interventora, controladora e dominadora, coerentemente com as características da racionalidade científica moderna em geral: "racionalismo, mecanicismo, dualismo, fragmentarismo, metodologismo, quantitativismo, materialismo" (Luz, 1988, p.117). Com isso, busca controlar o corpo, eliminar ou controlar doenças, fazer a gestão dos riscos, regulamentar modos de vida.

A biomedicina adotou, de forma hegemônica, a metafísica materialista, o que induz e aprofunda a afinidade eletiva entre o esquema de valor do controle na sociedade moderna e na ciência médica. Essa metafísica afirma que o mundo "realmente é" tal e qual todos os objetos presentes nele (inclusive os seres humanos) são inteiramente caracterizáveis por propriedades e relações materialistas (talvez, em última análise, fisicalistas): todos os fenômenos são inteiramente caracterizáveis sob o aspecto de sua produção pelas estruturas, processos e leis subjacentes, e as possibilidades das coisas são exauridas por suas possibilidades materiais. Então, a adesão às estratégias materialistas poderia conduzir-nos a uma explicação completa do mundo (Lacey, 1998).

O entendimento do mundo é obtido, aí, por um tipo de conhecimento específico da ciência: as teorias. Estas, em geral restritas pela estratégia materialista ${ }^{5}$, representam os fenômenos em termos de sua concordância com leis da natureza (física e biológica), e apresentam uma imagem do mundo em termos de leis e quantidades. Os fenômenos são abstraídos de qualquer inserção na experiência humana, nas atividades práticas e sociais. As teorias deixam inexploradas, na maior parte, tanto as condições (mesmo as sociais) que criam e mantêm os espaços a respeito dos quais elas fornecem entendimento, quanto os efeitos e consequências dos acontecimentos de tais espaços nos ambientes naturais, humanos e sociais (Santos, 2000; Lacey, 1998).

Em outras palavras, diz-se que as teorias científicas produzem conhecimento "extensivo", isto é, relacionam muitos acontecimentos aparentemente desconectados e diferentes. Conectam, por exemplo, o movimento de uma flecha ao movimento dos planetas e dos corpos em queda. Na ciência, a extensividade é um valor cognitivo prestigiado: tanto melhor uma teoria quanto mais fenômenos ela interligar e explicar, e assim, subliminarmente, permitir previsão e mecanismos de controle. Todavia, as teorias científicas não produzem conhecimento "completo". Se a ciência pode prever com boa aproximação a trajetória da flecha, não relaciona a flecha ao arqueiro, à vitima, ao fabricante de arcos, à matéria-prima usada na sua confecção, ao contexto social e ao objetivo do tiro
${ }^{6}$ Existem outras teorias com outras estratégias de seleção de dados, mesmo na biomedicina, como, por exemplo, a psicanálise. São de localização e difusão suficientemente pequena e marginal na profissão médica para confirmarem a regra. 
${ }^{7}$ Um exemplo trivial é o conceito de inflamação, que unifica os mais distintos e variados fenômenos corporais e mórbidos, sem dúvida de forma precária, mas permite seu controle relativo por meio dos anti-inflamatórios (hormonais e nãohormonais), base de boa parte das terapêuticas biomédicas. Eles são potentes como sintomáticos, mas pouco duradouros e apresentam relevante iatrogenia. (uma guerra? uma caçada? um esporte?). Um conhecimento completo envolveria essas finalidades, sujeitos, histórias e suas relações.

Se a extensividade do conhecimento científico encanta e seduz, gerando o avanço tecnológico, a sua incompletude, na área da saúde, tem desdobramentos sérios, raramente discutidos. Na relação da sociedade com a ciência e a tecnologia, a incompletude já exige atenção, é motivo de algum debate público, de legislação específica e de interesse dos cidadãos, devido, sobretudo, à crise ecológica e ambiental global. Na saúde, a nossa hipótese é de que a percepção da incompletude do saber científico se manifesta pela fuga para outras medicinas, mas permanece fora da ciência e da corporação médica. Para além da má prática, isso remete aos dilemas e cegueiras paradigmáticas na diagnose e na ação terapêutica, em que o conhecimento científico parece ser pobre em completude e está, a toda hora, se debatendo com a complexidade e integração dos aspectos e partes das pessoas e seus adoecimentos, sendo que essa complexidade e integração não são abrangidas ou são excessivamente reduzidas pela extensividade das teorias biomédicas atuais e suas tecnologias correlatas ${ }^{7}$. O baixo teor de "integralidade" dessa medicina (Tesser, Luz, 2008) está enraizado nessa desproporção extensividade-completude, em que o controle tem papel fundamental.

Entender o papel e o valor do controle na ciência prepara o terreno para entendermos o controle no saber médico e na biomedicina. Se ele já está hipertrofiado pela tradição hospitalar, pela luta contra a natureza e as doenças e pelo autoritarismo, atinge o ápice quando da cientificização progressiva da medicina, que o sacraliza. Assim, há que compreender a poderosa e agressiva tendência controlista que permeia a biomedicina e se infiltra em grande parte da subjetividade médica, contribuindo para a má medicina, de certo modo afastando a solidariedade, diminuindo o empoderamento e a autoconfiança dos pacientes, dificultando a harmonia e a efetividade das práticas profissionais nos seus aspectos relacionais, de comunicação e educação.

Todavia, pouco há além do império do controle como valor social, político e científico que justifique a sua exportação como valor principal para clínica, exceto, é claro, a noção disseminada de que ele tem utilidade pragmática imediata, levada ingenuamente, contraprodutivamente e perigosamente até as últimas consequências. Ao contrário, pode-se pensar que talvez a obsessão pelo controle seja justamente um empecilho para a clínica, para sua missão "curadora" (Tesser, 2007), para o aprendizado do cuidado em meio à incerteza.

O controle como pivô da ação médica deve também ser levado em conta na consideração de sua ação alimentadora da medicalização social, geradora, por um lado, de dependência excessiva do cuidado médico-profissional (Illich, 1981), e, por outro, de disciplinarização dos comportamentos (Foucault, 1988, 1980) e dos cuidados com a saúde, introjetada até ser incorporada obsessivamente pela cultura geral e pelas pessoas (Nogueira, 2003), gerando o que Nogueira (2001) chamou de "higiomania".

Assim, a beligerante obsessão por controle que permeia a biomedicina e parte dos profissionais médicos vem de muitos "lados": das teorias e dos métodos científicos biomédicos; das tecnologias científicas; dos valores sociais, hospitalares e epistemológicos; dos interesses econômicos da indústria farmacêutica e de equipamentos; das lutas políticas científicas; da medicalização social. Uma tensão controlista atrapalha o relacionamento de parte dos médicos com os doentes, minando corações e mentes desses curadores, que reproduzem a beligerância controladora que aprenderam. 


\section{A ilusão do heroísmo solitário e sua missão impossível}

Como já mencionado, a biomedicina contemporânea trava uma batalha contra a doença e o sofrimento, num mundo supostamente hostil. Luta pelo controle do envelhecimento e da morte, das doenças do corpo ("orgânicas"), dos sintomas dos sofredores "não orgânicos", "mentais" e, recentemente, luta pelo controle dos riscos. Uma batalha contínua que pode ser considerada como heroica.

As práticas hospitalares formadoras dos médicos, já discutidas, são fortes geradores da sensação de heroísmo. Também as dificuldades da cura nãohospitalar contribuem para concretizar algo dessa sensação, pois suas tecnologias típicas deveriam operar com eficácia para os adoecimentos e dores ambulatoriais, mas deixam a desejar. Boa parte dos médicos vive o que pode ser ilustrado metaforicamente como uma saga de heróis, algo como uma missão imaginária, ou uma característica subcultural, que tem desdobramentos no cotidiano profissional.

Um desses desdobramentos relaciona-se a que bem pouco das promessas da modernidade e da ciência esse "herói" consegue realizar. Além disso, o processo de medicalização social progressiva ensina os doentes a cobrarem de seus médicos curas rápidas e certeiras por meio de exames, comprimidos e cirurgias. A precariedade, a incompletude e os limites do saber médico para a abordagem de boa parte dos adoecimentos do cotidiano ambulatorial frustram a ambos, supondo acesso aos recursos de diagnose. As tecnologias terapêuticas mais valorizadas, quimioterápicos e cirurgias, também são frustrantes em boa medida, além de muitas vezes iatrogênicas - ressalvada, é claro, sua eficácia em casos específicos, como traumas e infecções graves. Vale lembrar que há grande coerência dos procedimentos mais valorizados pela cultura, pela mídia, pelos pacientes e pelos profissionais com a adoção da estratégia materialista na biociência: se o que explica o mundo e as doenças são as relações estruturais e quantitativas entre os elementos materiais do corpo, nada mais lógico que intervenções deste tipo (como comprimidos e cirurgias) devam ser os potentes remédios para os consertos na biomáquina.

Ocorre que a maior parte da busca por atenção à saúde constitui-se de situações de gravidade baixa e média, muito diferentes da clientela e da morbidade hospitalar. Apresenta uma grande variedade de queixas e sintomas sobretudo dores -, sendo que apenas uma parcela deles consegue ser interpretada e enquadrada pelo saber biomédico na sua nosografia, ficando grande parte desconsiderada ou sem interpretação (Caprara, Rodrigues, 2004; Camargo Jr., 2003), travestida de um sinônimo técnico, em geral descritivo, que desemboca na prescrição de uma avalanche de sintomáticos. Como já dizia Balint (1988), os médicos valorizam mais as doenças físicas diagnosticáveis, às quais dão importância, tendendo a subvalorizar aspectos subjetivos, emocionais e sociais (para o que seu saber é limitado e incompleto, relativamente incompetente), o que alimenta a medicalização. Esse descompasso e limitação ajudam a criar a sensação de missão heroica, seja na ânsia de concretizar diagnósticos além de sindrômicos e descritivos, seja na ânsia de aliviar sofrimentos via quimioterapia ${ }^{8}$, seja, ainda, numa resignação incômoda na posição frequente de desenganar os pacientes e/ou desqualificar ou ignorar suas queixas.

Por outro lado, a biomedicina herdou também uma suposta solidão da ciência, como única e solitária instituição no mundo moderno a produzir verdades confiáveis. O heroísmo passa a ser solitário, uma vez que os curadores científicos estariam sozinhos, únicos especialistas sociais a resolverem os problemas de saúde das pessoas. E, com isso, alimenta-se a ilusão de uma missão impossível de onisciência e onipotência a cobrar dos médicos e de sua tecnologia "dura"

\author{
${ }^{8}$ Essa tendência é muito \\ forte devido à redução \\ progressiva, no saber \\ médico, do umbral \\ terapêutico para muitas \\ doenças, riscos e \\ condições, com redução \\ dos pontos de corte \\ (como para hipertensão e \\ diabetes), criação de \\ categorias \\ medicalizadoras \\ (exemplo: pré- \\ hipertensão, fibromialgia) \\ e expansão e \\ flexibilização de critérios \\ diagnósticos que ficam \\ mais abrangentes, que \\ vão medicalizando e \\ criando rótulos de \\ doenças para vivências e \\ sofrimentos os mais \\ diversos da vida, para os \\ quais a indústria \\ farmacêutica gera \\ incessantemente drogas \\ controladoras \\ sintomaticamente \\ eficazes (exemplo: \\ antidepressivos). Mas essa \\ é uma questão complexa \\ que transcende o escopo \\ deste texto.
}


poderes e curas quase milagrosos para todos os adoecimentos e padecimentos, acirrada com a medicalização social.

Adicionalmente, os médicos estão cada vez mais restritos na sua competência e autonomia epistemológica, reduzidos progressivamente a aplicadores de saberes e tecnologias investigativas (algoritmos diagnósticos) e terapêuticas institucionalizadas na biomedicina; perdendo sua identidade de curadores, que vai sendo substituída pela de técnicos obcecados por diagnósticos, administradores de tratamentos padronizados para doenças específicas. Eles tendem a ficar menos envolvidos, portanto, com a produção de compreensão e tratamento de seres individuais únicos sofrendo, com a vida e a saúde em crise (Dalmaso, 1998; Sayd, 1998; Luz, 1996).

Obviamente, tudo isso facilita a má medicina, estando inserido na complexidade da atividade médica em geral. Assim, alguns aspectos do cotidiano comum da má medicina podem ser interpretados como contendo influência da arrogância relacional e epistemológica desses curadores que se sentem heróis solitários; como, por exemplo, quando um médico diz para um paciente que sua doença "não tem cura" (mas tem controle, tratamento), situação cada vez mais comum - asma, rinite, hipertensão, reumatismos, diabetes, osteoartrites, dermatites, alergias, doenças ou transtornos mentais etc. Há aí uma conjunção de fatores: o monopólio institucional dessa corporação de curandeiros atribui aos mesmos certos poderes microssociais (institucionais) e reforça a arrogância e o autoritarismo aprendidos no hospital; a solidão social faz com que se sintam os únicos portadores "da" verdade; e, por último, a cegueira paradigmática alimenta a incapacidade de muitos praticantes de relativizar as verdades de seu saber, o que os induz a universalizá-las, tornando absolutas as verdades e limites biomédicos sobre as doenças, lançadas aos doentes como veredictos finais. Isso gera problemas e sofrimentos, para os doentes "desenganados" e "incuráveis", de crise de relacionamento, para os rebeldes e os não enquadráveis (que "não têm nada"), de desconfianças e de transtornos para todos.

Pairando única a produzir verdades sobre saúde-doença, não haveria sentido em reconhecer limites próprios à biomedicina e relativizar as más notícias, pois não existiria, nessa visão, nenhuma outra notícia a ser dada por nenhuma outra "tradição curadora" digna de crédito. Sem conseguir localizar os limites de seu saber, parte dos profissionais médicos muitas vezes "desenganam" os pacientes. Como consolo, a mídia promete, para breve, vários avanços tecnológicos e terapêuticos, pelos quais médicos e doentes devem esperar. Esses profissionais debatem-se, então, entre a precariedade dos recursos atuais e as promessas exageradas, vivendo como podem o mito do herói com sua "missão" solitária impossível de onisciência e onipotência. Uma dessas possibilidades de vivência, então, é rechaçar a missão impossível e, ao fazê-lo, negar o difícil compromisso e missão ético-sociais de curador, negar os aspectos profundamente humanos e "sacerdotais" do manejo do sofrimento, da doença e da morte, encarando a medicina como simplesmente mais uma profissão, o que pode resultar em indiferença e frieza para com o adoecimento e sofrimento, que passam a ser problemas técnico-profissionais regrados por condutas protocolares. Por outro lado, talvez apenas alguns emergencistas usufruam, com alguma frequência, da sensação de dever de herói cumprido ao saírem de seus plantões. Mas esses momentos são uma pequena minoria das atividades médicas.

\section{Considerações finais}

Compreender parcialmente desencontros vividos na medicina e na má medicina exige consideração de variáveis insólitas contextuais (como trabalhar após uma noite em claro num plantão agitado) e fatores complexos epistemológicos, subculturais, filosóficos, pedagógicos, históricos, políticos. Muitos desses fatores, aqui não abordados (como a busca de status social e poder econômico, a relação com a estrutura social mais geral, o medo do erro e dos processos, dentre outros), necessitam análise e consideração para a composição de um quadro compreensivo mais amplo da má medicina. As ideias aqui sintetizadas são apenas uma reflexão parcial sobre o tema. Mesmo assim podemos ter deixado uma impressão talvez excessivamente negativa da biomedicina, para além da má medicina. Há que corrigi-la: os médicos não são todos assim, sua medicina não é ruim e seus saberes e tecnologias muitas vezes são maravilhosos. Simplesmente não abordamos o lado luminoso, das virtudes e potências, das sabedorias, 
da dedicação, da vocação, da criatividade, do aprendizado, das alegrias e experiências intensamente humanas que fazem crescer e enriquecer as vidas de médicos e doentes, também presente na prática médica. O objetivo era abordar poucos aspectos problemáticos e complexos envolvidos na má medicina, inerentes à própria biomedicina. A análise deles e de outros fatores parece-nos necessária de ser mais desenvolvida para que se possa trabalhar na formação médica e na sua educação permanente de modo a minimizar a má medicina e fomentar a boa medicina.

\section{Referências}

ADAM, P.; HERZLICH, C. Sociologia da doença e da medicina. Bauru: Edusc, 2001.

BALINT, M. O médico, seu paciente e a doença. Rio de Janeiro: Atheneu, 1988.

BOURDIEU, P. A economia das trocas simbólicas. São Paulo: Perspectiva, 1994.

CAMARGO JÚNIOR, K.R. A relevância do uso de técnicas qualitativas em pesquisas sobre a biomedicina. Cienc. Saude Colet., v.13, n.4, p.1327-30, 2008.

2003.

Biomedicina, saber e ciências: uma abordagem crítica. São Paulo: Hucitec,

CAMPBEL, J. As transformações do mito através do tempo. São Paulo: Cultrix, 1993.

CAPRARA, A.; RODRIGUES, J. A relação assimétrica médico-paciente: repensando o vínculo terapêutico. Cienc. Saude Colet., v.9, n.1, p.139-46, 2004.

CAPRARA, A.; FRANCO, A.L.S. A relação paciente-médico: para uma humanização da prática médica. Cad. Saude Publica, v.15, n.3, p.647-54, 1999.

CLAVREUL, J. A ordem médica: poder e impotência do discurso médico. São Paulo: Brasiliense, 1983.

CUNHA, G.T. A construção da clínica ampliada na atenção básica. São Paulo: Hucitec, 2005.

DALMASO, A.S.W. Estruturação e transformação da prática médica: técnica e ciência na segunda metade do século XX. 1998. Tese (Doutorado) - Faculdade de Medicina, Universidade de São Paulo, São Paulo. 1998.

FEYERABEND, P. Adeus à razão. Lisboa: Edições 70, 1991.

FLECK, L. La génesis y el desarrollo de um hecho científico. Madrid: Alianza Editorial, 1986.

FOUCAULT, M. História da sexualidade: a vontade de saber. Rio de Janeiro: Graal, 1988. v.1.

O nascimento da clínica. 2.ed. Rio de Janeiro: Forense Universitária, 1980.

GOFFMANN, E. Manicômios, prisões e conventos. São Paulo: Perspectiva, 1974.

GUEDES, C.R.; NOGUEIRA M.I.; CAMARGO JÚNIOR, K.R. A subjetividade como anomalia: contribuições epistemológicas para a crítica do modelo biomédico. Cienc. Saude Colet., v.11, n.4, p.1093-103, 2006. 
ILLICH, I. A expropriação da saúde: nêmesis da medicina. 4.ed. São Paulo: Nova Fronteira, 1981.

KLOETZEL, K.Medicina Ambulatorial: princípios básicos. São Paulo: EPU, 1999.

LACEY, H. Valores e atividade científica. São Paulo: Discurso Editorial, 1998.

LATOUR, B. A esperança de Pandora: ensaios sobre a realidade dos estudos científicos. Bauru: Edusc, 2001.

Ciência em ação: como seguir cientistas e engenheiros sociedade afora. São Paulo: Editora da Unesp, 2000a.

Jamais fomos modernos: ensaios de antropologia simétrica. 2.reimpr. Rio de Janeiro: Editora 34, 2000b.

LE FANU, J. The rise and fall of modern medicine. London: Carroll \& Graf, 2000.

LÉVI-STRAUSS, C. O pensamento selvagem. 2.ed. São Paulo: Companhia Editora Nacional, 1976.

LUZ, M.T. Racionalidades médicas e terapêuticas alternativas. Rio de Janeiro: Instituto de Medicina Social/UERJ, 1996. (Série Estudos em Saúde Coletiva, 62)

Natural, racional, social: razão médica e racionalidade científica moderna. Rio de Janeiro: Campus, 1988.

MARTINS, A. Filosofia e saúde: método genealógico e filosófico-conceitual. Cad. Saude Publica, v.20, n.4, p.950-8, 2004.

MENDES GONÇALVES, R.B. Reflexão sobre a articulação entre investigação epidemiológica e a prática médica a propósito das doenças crônico-degenerativas. In: CZERESNIA, D. (Org.). Epidemiologia: teoria e objeto. 2.ed. São Paulo: Hucitec/ Abrasco, 1994. p.39-86.

MÜLLER, M.L. Vittorio Hösle: uma filosofia da crise ecológica. Cadernos de história e filosofia da ciência. Série 3, vol. 6, n.2, p.9-62, jul-dez, 1996.

NOGUEIRA, R.P. A saúde pelo avesso. Natal: Seminare, 2003.

Higiomania: a obsessão com a saúde na sociedade contemporânea. In: VASCONCELOS, E. (Org.). A saúde nas palavras e nos gestos: reflexões da rede educação popular e saúde. São Paulo: Hucitec, 2001. p.63-72.

PIRES, F.D.A. Assistência médica alternativa: comentários a um texto de apoio. Cad. Saude Publica, v.1, n.4, p.125-36, 1998.

SANTOS, B.S. Um discurso sobre as ciências. 4.ed. São Paulo: Cortez, 2006.

A crítica da razão indolente: contra o desperdício da experiência. 2.ed. São Paulo: Cortez, 2000.

. Introdução a uma ciência pós-moderna. Rio de Janeiro: Campus, 1982.

SAYD, J.D. Mediar, medicar, remediar: aspectos da terapêutica na medicina ocidental. Rio de Janeiro: Eduerj, 1998.

STEWART, M. et al. Patient-centered medicine: transforming the clinical method. London: Sage Publications, 1995.

TESSER, C.D. Contribuições da epistemologia de Kuhn e Fleck para reforma do ensino médico. Rev. Bras. Educ. Med., v.32, n.1, p.98-104, 2008.

A verdade na biomedicina, reações adversas e efeitos colaterais: uma reflexão introdutória. Physis, v.17, n.3, p.465-84, 2007. 
TESSER, C.D. Epistemologia contemporânea e saúde: a luta pela verdade e as práticas terapêuticas. 2004. Tese (Doutorado) - Departamento de Medicina Preventiva e Social, Faculdade de Ciências Médicas, Universidade Estadual de Campinas, Campinas. 2004. Disponível em: <http://libdigi.unicamp.br/document/?code=vtls000317960>. Acesso em: 18 nov. 2008.

TESSER, C.D.; LUZ, M.T. Racionalidades médicas e integralidade. Cienc. Saude Colet., V.13, n.1, p.195-206, 2008.

TURNER, F.W. O espírito ocidental contra a natureza: mito, história e as terras selvagens. Rio de Janeiro: Campus, 1990.

TESSER, C.D. Tres consideraciones sabre la "mala medicina". Interface - Comunic., Saude, Educ., v.13, n.31, p.273-86, out./dez. 2009.

Realizamos algunas consideraciones sabre la "mala medicina": un grupo de fenómenos individuales y colectivos referentes a la falta de armonía común, insatisfacción y frustración, en el encuentro médico-paciente vividos por los enfermos. Con la intención de contribuir para una mejor comprensión de esta "mala medicina", consideramos su complejidad para llegar a sua mejoría. Divergimos del sentido común y docto que resume tales desencuentros como "mala práctica" médica. Argumentamos que algunos de sus aspectos típicos como autoritarismo arrogancia, frieza, actitud de control, beligerancia, sensación de omnipotencia y omnisciencia de muchos médicos, están entrelazados con fuerzas factores histórico-epistemológicos, socio-políticos y subculturales de estos profesionales, como la victoria política de la Ciencia y su etnocentrismo, el monopolio oficial de la curación por la biomedicina, la vigencia y expapsión en ella de un paradigma biomecánico, la cultura autoritaria hospitalaria, la adopción ciega del preconcepto científico con la no-ciencia, entre otros factores; además de procesos más amplios y complejos como la medicación social.

Palabras clave: Medicina. Relaciones médico-paciente. Mala conducta profesional. Sociología. Antropología. 